\title{
Changes in enzyme activity in normal and histologically inflamed oesophageal epithelium
}

\author{
D. HOPWOOD, P. E. ROSS, KATHLEEN R. LOGAN, G. NICHOLSON, AND \\ I. A. D. BOUCHIER
}

From the Departments of Pathology and Medicine, Ninewells Hospital and Medical School, Dundee

SUMMARY Oesophageal biopsies were obtained from 74 patients undergoing upper gastrointestinal fibreoptic endoscopy. Thirteen patients with histological evidence of inflammation had a raised alkaline phosphatase activity $(2.7 \pm 1.6 \mathrm{nmol} / \mathrm{mg}$ protein $/ \mathrm{min})$ compared with 49 normal controls $(1.2 \pm 0.68 \mathrm{nmol} / \mathrm{mg}$ protein $/ \mathrm{min}: \mathrm{P}<0.001)$. The acid phosphatase level was lower $(8.4 \pm 4.0 \mathrm{vs} 5.8 \pm 2.2$ $\mathrm{nmol} / \mathrm{mg}$ protein $/ \mathrm{min}: \mathrm{P}<0.05)$ and the glucuronidase activity raised $(0.44 \pm 0.17 \mathrm{vs} 0.81 \pm 0.32 \mathrm{nmol} /$ $\mathrm{mg}$ protein $/ \mathrm{min}: \mathrm{P}<0.001)$ and their ratio declined $(24.0 \pm 1.9 \mathrm{nmol} / \mathrm{mg}$ protein $/ \mathrm{min}: \mathrm{P}<0.001)$ in patients with oesophagitis. This may be due to differential secretion of membrane coating granules, a form of lysosome found in oesophageal epithelium. The extension of the basal cell compartment another criterion of oesophagitis - was assessed by point counting. The volume density rose from $10.9 \pm 4.25 \%$ in normal biopsies to $46.4 \pm 12.5 \%(\mathrm{P}<0.001)$ in oesophagitis. These results show a consistent pattern that possibly indicates an intermediate stage between the clinically, histologically, and biochemically normal oesophagus and one that is inflamed on endoscopy.

There are difficulties for the pathologist in determining the presence and extent of inflammation in oesophageal biopsies obtained in fibreoptic endoscopy. These are related to the size and orientation of the specimen. In order to overcome this problem, various new criteria to establish the diagnosis have been introduced (Ismail-Beigi and Pope, 1970; Kobayashi and Kasugai, 1974). Nevertheless, the ranking of biopsies remains difficult and time consuming.

In a histochemical survey of phosphatase activity in normal human oesphageal biopsies, we noticed that alkaline phosphatase activity was confined to capillary endothelium (Logan et al., 1978). As an increase in capillary length and number is a feature of inflammation (Ismail-Beigi et al., 1970; Kobayashi et al., 1974) we postulated that there should be a parallel increase in alkaline phosphatase activity in oesophagitis. We have also shown that normal human oesophageal epithelium is rich in membranecoating granules which are part of the lysosomal system (Hopwood et al., 1978) and it seemed probable that during inflammation there would be a change in lysosomal enzyme activity.

We therefore obtained oesophageal biopsies from patients with endoscopically normal and inflamed

Received for publication 10 April 1979. oesophaguses and subjected them to histometric and biochemical analysis. We related the degree of inflammation assessed morphologically to the alkaline phosphatase activity of the capillaries and the $\beta$-glucuronidase and acid phosphatase activity as markers of lysosomes of the oesophageal epithelium.

\section{Methods}

PATIENTS

Oesophageal biopsies were obtained from 74 patients who were undergoing upper gastrointestinal endoscopy as part of a clinical evaluation. All patients were assessed by a history and physical examination, an oesophagoscopy using either a forward-viewing ACMI F8 or an oblique-viewing Olympus GIF-K fibreoptic endoscope, and an oesophageal biopsy using the appropriate biopsy forceps. Biopsies were taken $8-10 \mathrm{~cm}$ above the gastro-oesophageal junction (Ismail-Beigi and Pope, 1974). At least two biopsies were obtained from each subject. This study was approved by the Tayside Health Board Ethical Committee.

The biopsies were immediately cut into two pieces with a fresh razor blade; one portion was fixed in

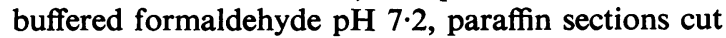
and stained with $\mathrm{H}$ and $\mathrm{E}$, the other was analysed 
biochemically. The sections were assessed for inflammation without knowledge of the biochemical or clinical findings, using the criteria of IsmailBeigi et al., (1970) and Kobayashi et al., (1974). The presence and amount of lamina propria was determined and, if it was more than one-tenth the area of the section, the specimen and patient were rejected from the study.

The patients were classified into a normal or oesophagitis group according to the histological appearance of the biopsy. Fourteen patients (age range 20-75 years) showed evidence of oesophagitis; 60 patients (age range 19-70 years) had normal appearances on light microscopy of the biopsy.

Glycogen, which is absent only from the basal cells (Hopwood et al., 1977), was demonstrated by the PAS technique (Pearse, 1968). This technique usefully divides the epithelium into two compartments which may then be assessed histochemically.

\section{POINT COUNTING}

The volume density of the basal cell compartment, prickle with functional cells and papillae, was determined by point counting using a 121 point assay eye piece graticule with $a \times 10$ eye piece and $a \times 40$ objective lens. This was placed sequentially, but without overlap, over the sections. The points falling in the various layers of the mucosa were counted and their volume densities calculated. A fuller account of this technique is given by Skinner and Whitehead (1976). The theoretical accuracy of the point counting can be estimated using the equation given by Weibel (1963).

$$
P_{T}=\frac{0.453(\mathrm{I}-\mathrm{Vv})}{\mathrm{Vv}(\mathrm{E} . \mathrm{Vv}) 2}
$$

where $P_{T}$ is the number of points counted, $V_{v}$ the volume density, and EVv the error. Preliminary counts showed the volume density of the basal and suprabasal compartments varied between 10 and $60 \%$. If between 500 and 600 points are counted, this give an error of $5 \%$. At least 600 points were counted from four or more sections of the oesophageal biopsy from each patient.

\section{BIOCHEMISTRY \\ Materials}

The flurogenic substrates, 4-methylumbelliferyl-a-Dglucuronide trihydrate and 4-methylumbelliferyl phosphate, were supplied by Koch-Light Laboratories Ltd., Colnbrook, Bucks. Other chemicals were 'AR' grade supplied by BDH Chemicals Ltd., Poole, Dorset.

\section{TECHNIQUES}

Tissue homogenates

Only small amounts of tissue were available (typi- cally $0.5-1.5 \mathrm{mg}$ wet weight) and consequently the total sample was homogenised in $1.0 \mathrm{ml}$ of ice-cold saline using a hand-driven Teflon pestle in a glass tube. Cellular debris was removed by centrifugation at $600 \times g$ for 10 minutes and the supernatant used for enzyme assays.

\section{Enzyme assays}

Fluorimetric assays were based on the release of 4-methylumbelliferone from either 4-methylumbelliferyl phosphate or 4-methylumbelliferyl- $\beta$-Dglucuronide. The fluorescence of this product was measured in phosphate buffer (pH 10.4) at $365 \mathrm{~nm}$ activation and $440 \mathrm{~nm}$ emission using a Baird Atomic Fluoricord spectrophotofluorimeter.

Alkaline phosphatase (EC3.1.3.1) activity was assayed by a modification of the method of Fernley and Walker (1965). The incubation volume was reduced to $1.0 \mathrm{ml}$ comprising $0.85 \mathrm{ml}$ tris buffer (pH 9.0, $0.005 \mathrm{~mol} / \mathrm{l}$ ) containing albumen $0.1 \mathrm{~g} / \mathrm{l}$, $0.05 \mathrm{ml}$ homogenate, and $1.0 \mu \mathrm{mol} \mathrm{4-methylumbel-}$ liferyl phosphate. After incubation at $37^{\circ}$ for 15 minutes, $1 \mathrm{ml}$ was removed and mixed thoroughly

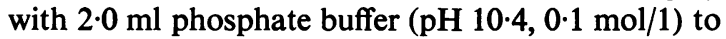
stop the reaction and adjust the $\mathrm{pH}$ for maximum fluorescence.

Acid phosphatase (EC 3.1.3.2) activity was assayed similarly, using an acetate buffer $(\mathrm{pH} \mathrm{4.9}, 2 \mathrm{~mol} / \mathrm{l})$ for incubation.

Assays of $\beta$-glucuronidase (EC3.2.1.31) activity were based on the method of Mead and his colleagues (1955). The incubation volume was again $1.0 \mathrm{ml}$ and consisted of $0.85 \mathrm{ml}$ acetate buffer $(\mathrm{pH} 5 \cdot 3,0 \cdot 1 \mathrm{~mol} / 1$ $0.05 \mathrm{ml}$ homogenate, and $1.0 \mu \mathrm{mol}, 4$-methylumbelliferyl- $\beta$-D-glucuronide.

Blanks were assayed with all samples to assess both endogenous fluorescence of the tissue homogenate and non-enzymic hydrolysis of the substrates. Standards of 4-methylumbelliferone were also assayed and enzyme activity was standardised against chromatographically pure alkaline phosphatase (Miles Laboratories Ltd., England).

In the experimental conditions used for this study a linear increase in the concentration of 4-methylumbelliferone was produced by an increase of up to five times in homogenate concentration and up to one hour in incubation time. As the activity of $\beta$ glucuronidase was generally lower than acid or alkaline, phosphatase activity of this enzyme was determined after 30 minutes' incubation compared with 15 minutes' incubation for the phosphatases.

Enzyme activities, expressed as nmol/mg protein min/incubation are shown in the Table as a mean \pm standard deviation.

Enzyme activity was related to the homogenate protein concentration determined by the method of 
Table Biochemical and histometric analyses of biopsies from normal and oesophagitic epithelium

\begin{tabular}{|c|c|c|c|c|c|c|}
\hline & & $\begin{array}{l}\text { Alkaline } \\
\text { phosphatase }\end{array}$ & $\begin{array}{l}\text { Acid } \\
\text { phosphatase }\end{array}$ & $\beta$-glucuronidase & $\begin{array}{l}\text { Acid phosphatase } \\
\beta-\text { glucuronidase }\end{array}$ & $V_{v}$ basal cells \\
\hline Normal & $\begin{array}{l}\text { Mean } \\
\mathrm{n}\end{array}$ & 40 & $\begin{array}{l}8 \cdot 4 \pm 4 \cdot 0 \\
49\end{array}$ & $\underset{41}{0.44 \pm 0.17}$ & $\begin{array}{l}24 \cdot 0 \pm 7 \cdot 6 \\
24\end{array}$ & $\begin{array}{l}10 \cdot 9 \pm 4 \cdot 25 \\
10\end{array}$ \\
\hline $\begin{array}{l}\text { Inflamed } \\
\mathbf{P}\end{array}$ & $\begin{array}{l}\text { Mean } \\
\mathrm{n}\end{array}$ & $\begin{array}{l}2.7 \pm 1.6 \\
10 \\
<0.001\end{array}$ & $\begin{array}{l}5 \cdot 8 \pm 2 \cdot 2 \\
13 \\
<0.05\end{array}$ & $\begin{array}{l}0.81 \pm 0.32 \\
13 \\
<0.001\end{array}$ & $\begin{array}{l}7.37 \pm 1.9 \\
13 \\
<0.001\end{array}$ & $\begin{array}{l}46.4 \pm 12.5 \\
12 \\
<0.001\end{array}$ \\
\hline
\end{tabular}

Lowry et al., (1951) using $0 \cdot 1 \mathrm{ml}$ homogenate for this assay.

\section{STATISTICAL ANALYSIS}

The results were analysed using Student's $t$ test. Ratios were compared by the Mann-Whitney U test.

\section{Results}

Fourteen patients demonstrated histological evidence of oesophagitis of whom 12 had complete biochemical evaluation. Of these, four gave symptoms suggestive of oesophageal disease: either retrosternal pain, heartburn, or dysphagia. Three of these patients had endoscopic appearances indicative of oesophagitis: a red, oedematous, and friable mucosa. The oesophagus appeared normal at the time of endoscopy in the remaining patients.

Alkaline phosphatase activity associated with

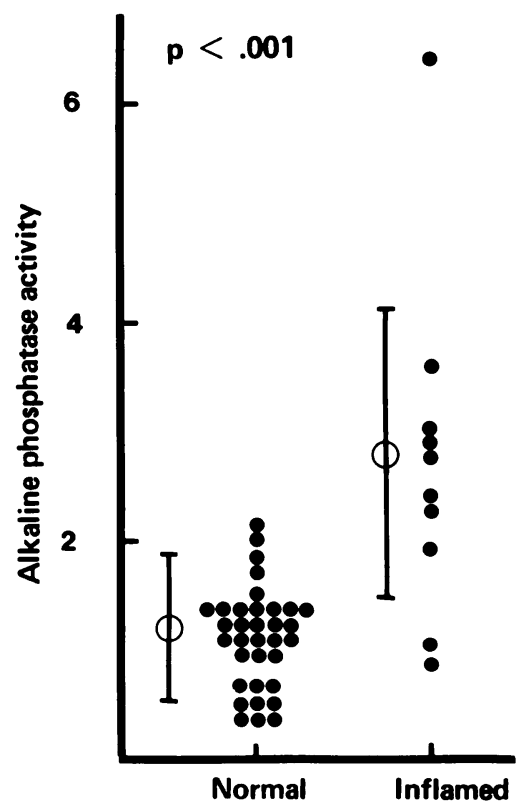

Fig. 1 Alkaline phosphatase activity nmol/mg protein/ min in oesophageal biopsies from patients with (10) and without (34) histological evidence of oesophagitis. capillary endothelium was increased twofold from $1.2 \pm 0.68$ to $2.7 \pm 1.6 \mathrm{nmol} / \mathrm{mg}$ protein $/ \mathrm{min}$ in inflamed tissue $(\mathrm{P}<0.002$, Fig 1$)$. The lysosomal enzyme-glucuronidase showed a similar increase, although the overall level was lower, increasing from $0.44 \pm 0.17$ to $0.81 \pm 0.32 \mathrm{nmol} / \mathrm{mg}$ protein $/ \mathrm{min}$ $(\mathrm{P}<0.001$, Fig 2). However, acid phosphatase, which is also a lysosomal enzyme, showed a decreased activity in inflamed tissue, falling from $8.4 \pm 4.0$ to $5.8 \pm 2.2 \mathrm{nmol} / \mathrm{mg}$ protein $/ \mathrm{min}(\mathrm{P}<0.05$, Fig 2$)$.

In view of the opposite changes found in activity of the two lysosomal enzymes, enzyme activity was expressed as the ratio acid phosphatase $\beta$-glucuronidase, and this ratio fell from 24 to $7 \cdot 37$ for inflamed tissue $(\mathrm{P}<0.001$, Fig 2$)$.

\section{HISTOMETRY}

Analysis of the PAS stained sections from the normal and inflamed biopsies shows a fourfold increase in the means of the volume density basal cell compartment in the inflamed state $(46.6 \pm 12.5 \%)$ compared with the normal $(10.9 \pm 4.25 \%)(\mathrm{P}<0.001$, Fig 3$)$.

The biopsies from the oesophagitis patients were plotted by the volume density of basal cell compartment against the ratio of acid phosphatase/ $\beta$ glucuronidase activity. The plot showed a negative slope $(r=0.71)$. If values of the normal biopsies are added to the plot, then a curve results, which does not straighten out by plotting logarithmically (Fig 4).

\section{Discussion}

Oesophageal biopsies consist largely of epithelial cells with only a small volume contributed by the papillae and their contents. Microscopic control of the biochemical assays of the biopsies allowed those containing lamina propria to be rejected. For the histometric analysis, the problems were those of the orientation of the biopsy and its small size.

Normal material was taken from $10 \mathrm{~cm}$ above the gastro-oesophageal junction for reasons suggested by Ismail-Beigi et al., (1970). There are difficulties in identifying the site of biopsy. Endoscopically, it is not always possible to be certain of the position of the gastro-oesophageal junction, which resulted in a few gastric biopsies being taken. These 

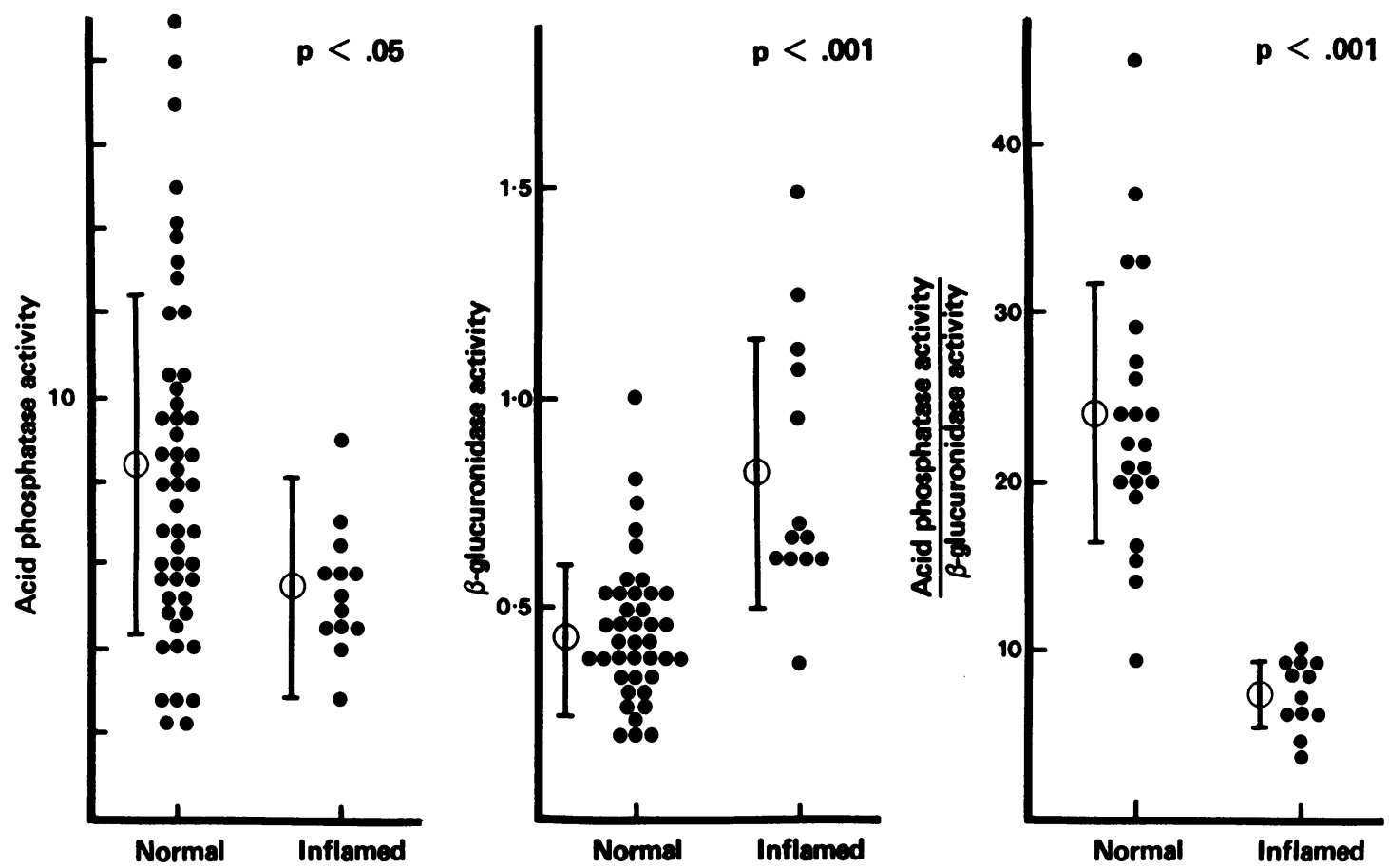

Fig. 2 Acid phosphatase activity in nmol/mg protein/min $\beta$-glucuronidase activity nmol/mg protein/min and their ratio in oesophageal biopsies taken from patients with and without histological evidence of oesophagitis.

were discarded on their histological appearances and also on their enzyme content, which showed an acid phosphatase/ $\beta$-glucuronidase ratio of 2 or less.

One of the criteria for diagnosis of oesophagitis is an increase in the basal cell compartment (IsmailBeigi et al., 1970; Kobayashi, 1974; Behar and Sheahan, 1975), which is concerned with cell replication (Marques-Pereira and Leblond, 1965). The rate of cell division has been shown to increase in oesophagitis (Livstone et al., 1977). The suprabasal cells contain glycogen (Hopwood et al., 1977, 1978) differentiating them from the basal cells. The glycogen may easily be demonstrated with the PAS reaction, thus facilitating point counting. The basal cell compartment then may be determined by subtraction. Using these techniques, the biopsies from the normal patients were shown to contain more glycogen and were clearly separated from the oesophagitic biopsies. The mean volume density of the normal basal cells was $10.0 \%$ well within the $15 \%$ found by Ismail-Beigi et al., (1970) and Behar et al., (1975) by visual inspection. In the biopsies from histologically inflamed mucosa this increased to a mean of $46.4 \%$.

The elongation of capillaries into the upper onethird of the oesophageal epithelium is another criterion suggested for the diagnosis of oesophagitis (Ismail-Beigi et al., 1970; Behar et al., 1975). This

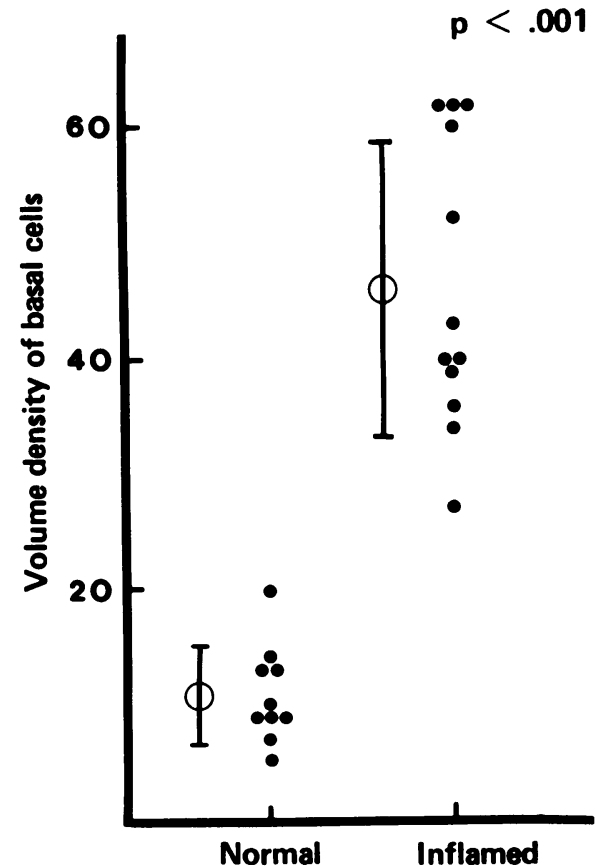

Fig. 3 Volume density of basal cells in oesophageal biopsies taken from patients with and without histological evidence of oesophagitis. 


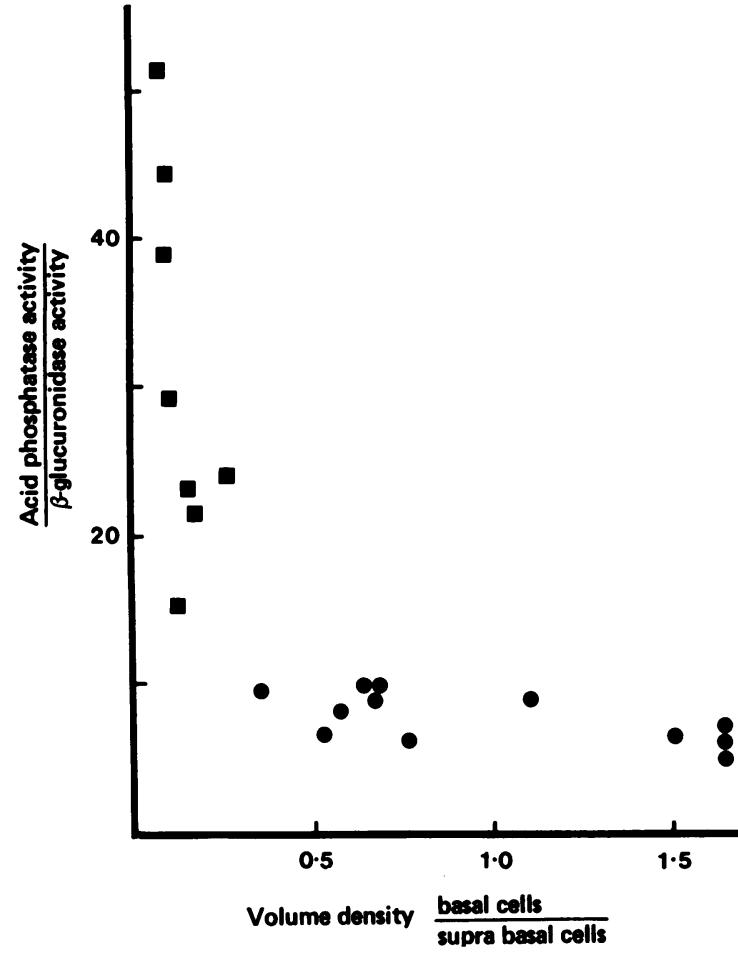

Fig. 4 Graph of the ratio acid phosphatase activity/ $\beta$-glucuronidase activity versus the ratio of the volume densities of basal cells/suprabasal cells. The points from the normal biopsies are to the left - the vertical component ( $)$ and those from the patients with oesphagitis from the lower horizontal group (O).

should give rise to an increase in alkaline phosphatase activity providing the enzyme is as active in the new longer endothelial loop cells as it is in the normal ones. This was found to be the case, this increase being just over twofold from normal. Alkaline phosphatase activity has been noted before in capillary endothelium, but its function remains obscure (Marchesi and Barrnett, 1963).

Lysosomal activity is commonly increased in cell injury and it seemed reasonable to determine whether this happened in the inflamed oesophageal epithelium. Our observations showed a decreased acid phosphatase activity and an increased $\beta$ glucuronidase activity when histologically inflamed biopsies were compared with tissue. This decreased acid phosphatase activity may be due to nonparallel secretion of enzymes similar to that demonstrated in the pancreas (Dagorn et al., 1977; Robberecht et al., 1977). We have previously shown that acid phosphatase is secreted into the intracellular space (Hopwood et al., 1978).

The increased $\beta$-glucuronidase activity in the histologically inflamed biopsies compared with the normal ones may be explained by differential packaging of the membrane coating granules and their non-parallel secretion. We have previously shown that there are different morphological types of membrane coating granules in the oesophageal epithelium (Hopwood et al., 1978). It has been suggested that the secretion of membrane coating granules may serve a local cellular reparative function (Wolff-Schreiner, 1977). Other protective mechanisms found in the inflamed oesophagus include parakeratosis and the appearance of tight junctions (Logan et al., 1978).

Although there was statistically significant separations of normal from histologically inflamed biopsies on either the acid phosphatase or $\beta$-glucuronidase activities, these were accentuated when the ratio of acid phosphatase/ glucuronidase activity was used. When this ratio was plotted against the morphometrically derived data for normal and histologically inflamed biopsies, a curve with two components was formed. The normal biopsies formed a vertical group, whereas the histologically inflamed ones produced a horizontal group, the endoscopically inflamed biopsies being the furthest from the normal biopsies.

The present study illustrates the discrepancy between clinical and endoscopic findings on the one hand and morphological and biochemical results on the other. This has been commented on previously by Thompson (1973) and Ismail-Beigi and Pope (1974). The biochemical and morphological results, however, show a consistent pattern, possibly indicating an intermediate stage between the clinically, histologically, and biochemically normal oesophagus and the endoscopically inflamed oesophagus.

We wish to thank Mrs. I. MacFarlane for secretarial help.

\section{References}

Behar, J., and Sheahan, D. C. (1975). Histologic abnormalities in reflux esophagitis. Archives of Pathology, 99, 387-391.

Dagorn, J. C., Sahel, J., and Sarles, H. (1977). Nonparallel secretion of enzymes in human duodenal juice and pure pancreatic juice collected by endoscopic retrograde catherization of the papilla. Gastroentero$\log y, 73,42-45$.

Fernley H. N., and Walker, P. G. (1969). Studies on alkaline phosphatase. Transient state and steady state kinetics of $\mathrm{E}$ coli alkaline phosphatase. Biochemical Journal, 111, 187-194.

Hopwood, D., Logan, Kathleen R., Bouchier, I. A. D. (1978). The electron micropsy of normal human oesphageal epithelium. Virchows Archiv B., 26, 345-358.

Hopwood, D., Logan, K. R., Coghill, G., and Bouchier, 
I. A. D. (1977). Histochemical studies of mucosubstances and lipids in normal human oesphageal epithelium. Histochemical Journal, 9, 153-161.

Hopwood, D., Logan, K. R., and Milne, G. (1978). The light and electron microscopic distribution of acid phosphatase activity in normal human oesphageal epithelium. Histochemical Journal, 10, 159-170.

Ismail-Beigi, F., Horton, P. F., and Pope, C. E., 2nd (1970). Histological consequences of gastroesophageal reflux in man. Gastroenterology, 58, 163-174.

Ismail-Beigi, F., and Pope, C. E., 2nd (1974). Distribution of the histological changes of gastroesophageal reflux in the distal esophagus of man. Gastroenterology, 66, 1109-1113.

Kobayashi, S., and Kasugai, T. (1974). Endoscopic and biopsy criteria for the diagnosis of esophagitis with a fibre-optic esophagoscope. American Journal of Digestive Diseases, 19, 345-352.

Livstone, E. M., Sheahan, D. G., and Behar, J. (1977). Studies of esophageal epithelial cell proliferation in patients with reflux esophagitis. Gastroenterology, 73, 1315-1319.

Logan, K. R., Hopwood, D., and Milne, G. (1978). Cellular junctions in human oesphageal epithelium. Journal of Pathology, 126, 157-163.

Lowry, O. H., Rosebrough, N. J., Farr, A. L., and Randall, R. J. (1951). Protein measurement with the Folin phenol reagent. Journal of Biological Chemistry, 193, 265-275.

Marchesi, V. T., and Barrnett, R. J. (1963). The demon- stration of enzymatic activity in pinocytic vesicles of blood capillaries with the electron microscope. Journal of Cell Biology, 17, 547-556.

Marques-Pereira, J. P., and Leblond, C. P. (1965). Mitosis and differentiation in the stratified squamous epithelium of the esophagus. American Journal of Anatomy, 117, 73-87.

Mead, J. A. R., Smith, J. N., and Williams, R. T. (1955). Studies in detoxification 67 . The biosynthesis of the glucuronides of umbelliferone and 4-methylumbelliferone and their use in fluorimetric determination of $\beta$-glucuronidase. Biochemical Journal, 61, 569-574.

Robberecht, P., Cremer, M., and Christophe, J. (1977). Discharge of newly synthesized proteins in pure juice collected from the human pancreas. Gastroenterology, 72, 417-420.

Skinner, J. M., and Whitehead, R. (1976). Immunological aspects of gastrointestinal pathology. Current Topics in Pathology, 63, 259-288.

Thompson, H. (1973). Symposium on gastroesophageal reflux and its complications. 2. The spectrum of pathological change. Gut, 14, 237-239.

Weibel, E. R., and Bolender, R. P. (1973). Stereological techniques for electron microscopic morphometry M. In Principles and Techniques of Electron Microscopy, vol. 3. Edited by M. A. Hayat. Van Nostrand Reinhold: London.

Wolff-Schreiner, E. C. (1977). Ultrastructural cytochemistry of the epidermis. International Journal of Dermatology, 16, 77-102. 